\title{
Polyphenol content and glycemic load of pasta enriched with Faba bean flour
}

\section{Imma Turco ${ }^{1 \S}$, Tiziana Bacchetti ${ }^{\S}$, Cecilia Bender ${ }^{3}$, Ganiyu Oboh ${ }^{4}$, Benno Zimmermann ${ }^{5}$, Gianna Ferretti ${ }^{1}$}

${ }^{1}$ Department of Clinical Experimental Science and Odontostomatology, Polytechnic University of Marche, Via Brecce Bianche, 60131 Ancona, Italy; ${ }^{2}$ Department of Life and Environmental Sciences, Polytechnic University of Marche, Via Brecce Bianche, 60131 Ancona, Italy; ${ }^{3}$ Institute Kurz Italy, Via Golfo dei Poeti 1/A, 43126 Parma, Italy, Institute Prof. Dr. Georg Kurz GmbH, Stöckheimer Weg 1, D-50829 Köln, Germany; ${ }^{4}$ Department of Biochemistry, Federal University of Technology, Akure, Ondo State, Nigeria; ${ }^{5}$ Institute Prof. Dr. Georg Kurz GmbH, Stöckheimer Weg 1, D-50829 Köln and Department of Nutritional and Food Sciences, Food Technology and Food Biotechnology, University of Bonn, Römerstraße 164, D-53117 Bonn, Germany

$\S:$ Both authors contributed equally to this work

*Corresponding author: Gianna Ferretti, Department of Clinical Experimental Science and Odontostomatology, Polytechnic University of Marche, Via Brecce Bianche, 60131 Ancona, Italy

Submission Date: March 30th, 2016, Accepted Date: May 27th, 2016, Publication Date: May 30,2016

\begin{abstract}
Background: Legumes contain elevated levels of health functional components. The objective of the present paper was to evaluate the nutritional properties and the post-prandial glycaemic responses of pasta obtained using 35\% Vicia Faba (VF) bean flour, which is an important source of fiber and phytochemical compounds.
\end{abstract}

Results: Protein and fiber content were higher in VF pasta compared with durum wheat semolina (DWS) pasta. The total phenol content in VF pasta was about two fold higher compared to that of DWS pasta. A higher total flavonoid content, higher antioxidant activity against peroxyl radicals evaluated by oxygen radical absorbance capacity (ORAC) assay was also observed in VF pasta. The comparison of post-prandial increase of glucose after VF intake or DWS demonstrated significant differences and VF pasta exhibited a lower glycemic index value, a lower glycemic load and higher glycemic profile compared with DWS pasta.

Conclusion: The results suggest that enrichment with 35\% Vicia faba bean has potential health benefits and that VF flour can be used as an ingredient to prepare added-value products.

Key words: Glycemic Index; Glycemic load; Glycemic Profile; polyphenols, flavonoids; diabetes 


\section{INTRODUCTION}

Pasta is an important staple food which is very popular in several countries around the world. Durum wheat semolina (DWS) is preferred for the production of different kinds of pasta. However, it is not nutritionally balanced, due to the low biological value of its protein. Moreover, durum wheat semoline is deficient in lysine and threonin, two essential amino acids. The amino acid and protein content can be improved by the inclusion of legume flours [1, 2]. Additionally, legumes are gaining interest because they are excellent sources of bioactive compounds such as flavonoids, isoflavones, and phenolic acids; therefore, they can be used as ingredients to produce added-value foods [2, 3]. Intake of legumes is reported to potentially lower the risk of cancer [4] and cardiovascular disease (CVD) [5].

Among the bioactive compounds contained in legumes, some molecules influence glucose metabolism, due to inhibition of enzymes involved in carbohydrate digestion (alfa-amylase and alfa-glucosidase), suppression of glucose absorption in the intestine, and stimulation of insulin secretion from pancreatic $\beta$ cell [6]. Since legumes are among the lowest glycemic index (GI) foods, they have been recommended in national diabetes mellitus (DM) guidelines. The concept of glycemic index was introduced by Jenkins in 1981, which allows for the ranking of different foods according to their glycemic response [7]. Elevated postprandial glucose levels and persistent hyperglycemia can lead to cellular damage and are associated with the development of retinal, renal, neurological and cardiovascular diseases [8]. Therefore, there is significant scientific and popular interest in the role of low glycaemic index foods and their role in prevention of chronic diseases [9-11].

Among legumes, there has been a growing interest in the Vicia faba bean, also known as the broad bean. The Faba bean (Vicia faba L.) is one of the major winter-sown legume crops and has an important place in the traditional diets of the Mediterranean, Indian, Chinese, English, Middle Eastern, African, South American. As a low-cost food rich in proteins and carbohydrates, the Faba bean is considerably important.

Vicia faba composition in nutrients and polyphenolic compounds has been previously studied [12-16]. From these studies, it has been suggested that this legume has a potential interest for newly designed food products due to its beneficial health implications [4]. Among bioactive properties exerted by Vicia faba polyphenols, in particular their antioxidant role $[4,14,15]$ and ability to inhibit activity of enzymes involved in carbohydrate digestion, have also been demonstrated in vitro [16]. There are no studies reporting the effect of the addition of Vicia faba bean flour to semolina on antioxidant and nutritional properties of pasta. The objectives of the present study were to evaluate levels of total polyphenols, flavonoids and antioxidant properties of pasta obtained using 35\% Vicia faba bean flour. We also evaluated the ability of pasta extracts to inhibit enzymes involved in carbohydrate digestion (alfa-amylase and alfa-glucosidase) and determined the postprandial glycemic response and glycemic index of pasta containing Vicia faba bean flour.

\section{METHODS}

\section{Composition of pasta}

The study included two types of pasta (noodles) containing eggs (30\%) and different type of flours: i) pasta obtained with durum wheat semolina (DWS) and ii) pasta obtained by replacing 
$35 \%$ of the durum wheat semolina by Faba bean (FV) flour. Both kinds of products were dried at low temperatures (starting from $60{ }^{\circ} \mathrm{C}$ to lower temperatures for 14 hours). Macronutrient (lipids, carbohydrates, proteins) and fiber contents of both pasta products were determined in agreement with ISTISAN 96/34 of National Institute of Health (ISS)[17].

\section{Sample preparation}

Pasta samples (DWS and VF) were finely ground and used to prepare aqueous extracts following previous studies [18]. $4 \mathrm{~g}$ of powered samples were briefly soaked in $20 \mathrm{~mL}$ of distilled water overnight and then centrifuged for 10 minutes at $3000 \mathrm{rpm}$. The supernatant was then collected and used to evaluate total polyphenols, total flavonoids, Oxygen Radical Absorbance Capacity (ORAC), alfa-amylase and alfa-glucosidase inhibition assay.

\section{Total polyphenols content}

Total polyphenol concentration was evaluated for both extracts using the method of FolinCiocoltau [19]. Results are expressed in milligram of gallic acid equivalents (GAE) per $100 \mathrm{~g}$ of dry pasta [19]. All evaluations were repeated in triplicate using three samples of each kind of pasta.

\section{Total flavonoid content}

The total flavonoid content of the extracts was determined in agreement with Xu and Chang [20]. The results are expressed as $\mathrm{mg}$ of catechin per $100 \mathrm{~g}$ of dry pasta. All evaluations were repeated in triplicate using three samples of each kind of pasta.

\section{Oxygen Radical Absorbance Capacity (ORAC) assay}

The antioxidant capacity of pasta extracts was measured by the ORAC assay [21]. To summarize, samples were dissolved in phosphate buffer, and added in duplicate wells into a black multiwell plate containing a $10 \mathrm{nM}$ solution of fluorescein. Trolox dilutions (6.25 to 100 $\mu \mathrm{M})$ were used as reference standard and phosphate buffer as blanks. The plate was incubated for 30 minutes at $37{ }^{\circ} \mathrm{C}$, the background signal was determined and a $240 \mathrm{mM}$ solution of 2,2'Azobis [2-methylpropionamide] dihydrochloride was added into each well. Fluorescence measurements were taken (excitation $485 \mathrm{~nm}$ and emission $520 \mathrm{~nm}$ ) for an hour at $37^{\circ} \mathrm{C}$ (Fluostar Optima, BMG Labtech, Germany) and data were analyzed with MARS 2.0 software (BMG Labtech, Germany). ORAC values were expressed as mean \pm SEM and as $\mu$ mol of Trolox Equivalents (TE) per $100 \mathrm{~g}$ of dry pasta.

\section{alfa-Amylase inhibition assay}

alfa-Amylase inhibition assay was carried out as previously described [18]. $500 \mu \mathrm{L}$ of $0.02 \mathrm{M}$ sodium phosphate buffer ( $\mathrm{pH} 6.9$ with $0.006 \mathrm{M} \mathrm{NaCl}$ ) containing porcine pancreatic alfa-amylase (EC 3.2.1.1; $0.5 \mathrm{mg} / \mathrm{mL}$ ) were incubated at $25^{\circ} \mathrm{C}$ for 10 minutes in the absence (reference) and in the presence of extracts samples $(25-100 \mu \mathrm{L})$. Then, $500 \mu \mathrm{L}$ of $1 \%$ starch solution in $0.02 \mathrm{M}$ sodium phosphate buffer $(\mathrm{pH} 6.9$ with $0.006 \mathrm{M} \mathrm{NaCl}$ ) were added to each tube. The reaction mixture was incubated at $25^{\circ} \mathrm{C}$ for 10 minutes and stopped with $1.0 \mathrm{~mL}$ of dinitrosalicylic acid color reagent. Afterwards, the mixture was incubated in a boiling water bath for 5 minutes, and 
cooled to room temperature. The reaction mixture was then diluted by adding $10 \mathrm{~mL}$ of distilled water, and absorbance was measured at $540 \mathrm{~nm}$ using a spectrophotometer.

The alfa-amylase inhibitory activity was expressed as percentage inhibition (\%) as previously described [18]:

Inhibition $(\%)=\left[\left(\mathrm{Abs}_{\mathrm{ref}}-\mathrm{Abs}_{\text {sample }}\right) / \mathrm{Abs}_{\mathrm{ref}}\right] \times 100$

$\mathrm{Abs}_{\text {ref }}$ :Absorbance of the reference

$\mathrm{Abs}_{\text {sample }}$ :Absorbance of the test sample

The concentration of the extracts causing 50\% enzyme inhibition $\left(\mathrm{IC}_{50}\right)$ was calculated using non -linear regression analysis.

\section{alfa-Glucosidase inhibition assay}

Alfa-Glucosidase inhibition assay was performed as previously described [18]. Briefly, $100 \mu \mathrm{L}$ of alfa-glucosidase solution $(1 \mathrm{U} / \mathrm{ml})$ in $0.1 \mathrm{M}$ phosphate buffer $(\mathrm{pH} 6.9)$ was incubated at $25^{\circ} \mathrm{C}$ for 10 minutes in the absence (reference) and in the presence of extract samples $(100-200 \mu \mathrm{L})$. Then, $50 \mu \mathrm{L}$ of $5 \mathrm{mM}$ p-nitrophenyl- $\alpha$-D-glucopyranoside solution in $0.1 \mathrm{M}$ phosphate buffer ( $\mathrm{pH}$ 6.9) were added. The mixtures were incubated at $25^{\circ} \mathrm{C}$ for 5 minutes, before the absorbance was identified at $405 \mathrm{~nm}$ in a spectrophotometer. The $\alpha$-glucosidase inhibitory activity was expressed as percentage inhibition (\%) [18]:

Inhibition $(\%)=\left[\left(\mathrm{Abs}_{\text {ref }}-\mathrm{Abs}_{\text {sample }}\right) / \mathrm{Abs}_{\mathrm{ref}}\right] \times 100$

$\mathrm{Abs}_{\text {ref }}$ :Absorbance of the reference

$\mathrm{Abs}_{\text {sample }}$ :Absorbance of the test sample

The concentration of the extracts causing 50\% enzyme inhibition $\left(\mathrm{IC}_{50}\right)$ was calculated using non -linear regression analysis.

\section{In vivo evaluation of glycemic index (GI), glycemic load (GL) and glycemic profile (GP)}

Evaluation of glycemic index (GI) was completed according to the FAO/World Health Organization (WHO) guidelines [22]. Among methodologies employed to diminish the inter and intra-subject variability inherent in GI testing including the use of glucose rather than white bread during the standardization phase, standardization of meals the day prior to each visit, restricting the inclusion criteria to certain age and body mass index (BMI). An inherent personto-person variability in these results is expected and GI calculation as an average takes these factors into account [22].

\section{Subjects}

Healthy subjects $(n=13)$ were recruited. Informed consent was obtained from each subject before beginning the study. Exclusion criteria included being diagnosed with chronic or digestive diseases, food allergies, pregnancy, and taking medications or supplements likely to influence glucose metabolism or gastrointestinal wellbeing. No co-morbidities such as type 1 or 2 diabetes or other diseases of glucose metabolism were observed, as demonstrated by the serum levels of 
glycated hemoglobin ( HbAlc $<5 \%$ ). Clinical characteristics of controls are summarized in Table 1. Body mass index (BMI) and fasting glycaemia were normal in all subjects.

Table 1. Characteristics of subjects

\begin{tabular}{|l|l|}
\hline N. subjects & 13 \\
\hline Male/female & $2 / 11$ \\
\hline Age (years) & $31 \pm 10$ \\
\hline BMI (Kg/m ${ }^{2}$ ) & $23 \pm 4$ \\
\hline Basal glucose levels (mmol/L) & $4.97 \pm 0.4$ \\
\hline
\end{tabular}

\section{Design}

The volunteers attended each testing session after a 12 hour overnight fast, having been instructed to consume the same meal the evening before each test day, to not drink alcohol or perform vigorous physical exercise [23]. Each volunteer took part in the experiment on three non-consecutive days. On the first experimental day, subjects consumed glucose solution. As proposed by Brouns et al. [24], glucose solution used as the reference food (GI =100) was prepared by adding $50 \mathrm{~g}$ glucose to $250 \mathrm{~mL}$ water. The second day, they ingested boiled wheat VF past and the last day they ingested DWS pasta. The pasta portions were professionally prepared and contained $50 \mathrm{~g}$ of available carbohydrates. Both pasta samples were boiled in unsalted water.

All subjects consumed the provided pasta portion within 10 minutes with $500 \mathrm{~mL}$ of still water as the only beverage. They remained seated during the 2 hours of the study and were not permitted to further eat or drink until the end of session. Blood glucose concentrations were measured in capillary whole blood obtained by finger prick (Bayer-CONTOUR ${ }^{\circledR}$ XT blood glucose meter, Bayer) in the fasted state (time 0) and at 15, 30 45, 60, 90 and 120 min after consumption of the test product.

\section{Calculation of glycemic index (GI)}

The glycemic index of a given food reflects how much of its digestible carbohydrates raise blood glucose levels. It is defined as the incremental area under the blood glucose response curve (iAUC) after consumption of a portion of test food providing $50 \mathrm{~g}$ of the available carbohydrates, expressed as a percentage of the average iAUC to the same amount of carbohydrates from the reference food (glucose) ingested by the same subject on a separate occasion. The iAUC is the incremental area under the blood glucose response curve (calculated for 2 hours following the ingestion of the tested product: 0-120 minutes). The incremental area under the blood glucose response curve (iAUC) was calculated geometrically using the trapezoid rule, ignoring the area below the fasting baseline [22]. For each test food, the iAUC was expressed as a percentage of the mean iAUC of the iso-carbohydrate reference food glucose consumed by the same subject [22]. GI of a tested food is given by: iAUC test food/average iAUC reference food $\times 100$. 
Calculation of glycemic load (GL)

The glycemic load (GL) of pasta was calculated by multiplying the amount of carbohydrate contained in a portion of $70 \mathrm{~g}$ of pasta by the GI value of that food, which was then divided by 100.

\section{Calculation of Glycemic Profile (GP)}

In addition to evaluating GI and GL, we calculated the Glycemic Profile (GP). In fact, the GI does not take into account the shape of the glycemic response curve. Rosen et al. [25] proposed measuring the glycemic profile $(\mathrm{min} / \mathrm{mM})$ of the products to evaluate the course of post-meal glycaemia. The GP is defined as the duration of the incremental postprandial glycemic response divided by the glucose iPeak. iPeak is the incremental glucose peak calculated as maximum postprandial increase from baseline. Therefore, GP was calculated by the ratio between the time (minutes) during which the blood glucose was above fasting concentration and the iPeak (mM) of blood glucose for each subject and test meal.

\section{Sensory evaluation}

All subjects $(n=13)$ enrolled in the evaluation of glycemic index were asked to evaluate both kinds of pasta for each sensorial parameter including colour, aroma, softness, taste, and overall acceptance based on their degree of liking $(1=$ dislike very much; $2=$ dislike moderately; $3=$ dislike slightly; $4=$ neither like nor dislike; $5=$ like slightly; $6=$ like moderately; $7=$ like very much). The palatability was considered acceptable if their average scores were greater than 4 (neither like nor dislike).

\section{Statistical analysis}

Compositional analyses of pasta sample were repeated in triplicate using three samples of each kind of pasta. Data were reported as mean \pm SEM. The results of GI, GL and GP were expressed as mean \pm SEM of the values obtained from each subject. Student's t-test was used to evaluate differences. All tests were 2-tailed and a $\mathrm{p}<0.05$ level of significance was used to assess statistical significance (Microcal Origin 5.0, OriginLab, Northampton, MA).

\section{RESULTS}

\section{Nutritional properties and polyphenol content of pasta samples}

Nutritional properties of VF and DWS pasta are shown in Table 2. Protein and fiber content were higher in VF pasta compared with DWS pasta. The ratio amylose/amylopectin was higher in VF pasta. Total phenol content in VF pasta was three fold higher compared with DWS pasta $(185.3 \pm 8.2 \mathrm{mg} / 100 \mathrm{~g}$ vs $63.8 \pm 10.1 \mathrm{mg} / 100 \mathrm{~g}, \mathrm{p}<0.001)$. A higher level of total flavonoids was also observed $(28.7 \pm 1.3 \mathrm{mg} / 100$ vs $16.5 \pm 1.5 \mathrm{mg} / 100 \mathrm{~g}, \mathrm{p}<0.001)$. Moreover, VF pasta exhibited $20 \%$ higher antioxidant capacity compared with DWS pasta $(1017 \pm 19.9 \mu \mathrm{mol} \mathrm{TE} / 100 \mathrm{~g}$ vs 851 $\pm 24.6 \mu \mathrm{mol} \mathrm{TE} / 100 \mathrm{~g}, \mathrm{p}<0.001)$. 
Table 2. Nutritional and antioxidant properties of pasta obtained using by Vicia faba bean flour (VF) and pasta obtained with durum wheat semolina (DWS). *p $<0.001$ vs DWS pasta. Data are shown as mean \pm SEM. Analyses were repeated in triplicate using three samples of each kind of pasta. Lipids, carbohydrates, proteins, and fiber contents were determined in agreement with ISTISAN 96/34 of National Institute of Health (ISS) [17].

\begin{tabular}{|l|l|l|}
\hline & DWS Pasta & VF Pasta \\
\hline Carbohydrate (g/100g) & $71.4 \pm 1.0$ & $70.1 \pm 1.2$ \\
\hline Starch (g/100g) & $65.0 \pm 0.2$ & $61.5 \pm 0.4$ \\
\hline Amylose/Amylopectin & $26.8 / 73.2$ & $29.2 / 70.8$ \\
\hline Sugar (g/100g) & $2.3 \pm 0.3$ & $1.8 \pm 0.2$ \\
\hline Fiber (g/100g) & $3.2 \pm 0.3$ & $6.8 \pm 0.4^{*}$ \\
\hline Total Proteins (g/100g) & $14.2 \pm 0.4$ & $16.1 \pm 0.3^{*}$ \\
\hline Lipids (g/100g) & $4.2 \pm 0.1$ & $3.4 \pm 0.1^{*}$ \\
\hline Total phenols (mgGAE/100g) & $63.8 \pm 10.1$ & $185.3 \pm 8.2^{*}$ \\
\hline Total flavonoids (mg CE/100g) & $16.5 \pm 1.5$ & $28.7 \pm 1.3^{*}$ \\
\hline OR $A C$ ( $\boldsymbol{1}$ mol TE/100 g) & $859 \pm 24.6$ & $1017 \pm 19.9^{*}$ \\
\hline
\end{tabular}

\section{Postprandial glucose response}

\section{Glycemic index (GI) and glycemic load (GL)}

Fasting blood basal glucose concentrations in healthy subjects were $4.97 \pm 0.4 \mathrm{mmol} / \mathrm{L}$ (Table 1). Figure 1 shows the mean blood-post-prandial glucose response following consumption of two pasta samples and standard solution of glucose in healthy subjects. The comparison of postprandial glucose response demonstrated a peak value at $30 \mathrm{~min}$ and a return to baseline within two hours (Figure 1). The incremental Area Under the Curve (iAUC) of blood glucose response over 120 minute for healthy subjects are shown in Table 3. The iAUC value was significantly lower in VF pasta $(\mathrm{p}<0.008)$. The glycemic index of VF pasta was $40 \pm 4.5$ while the control pasta demonstrated a higher value: $72 \pm 8(\mathrm{p}<0.002)$ (Table 3). Additionally, the glycemic load (GL) of VF pasta was significantly lower compared with control pasta $(p<0.002)$. The GP value of VF pasta was higher with respect to DWS pasta (Table 3). 
Figure 1 Postprandial glucose response in healthy subjects. (Continuous line $=$ standard glucose solution; broken line $=$ DWS pasta; dashed line $=$ VF pasta). (Data are presented as mean \pm SEM)

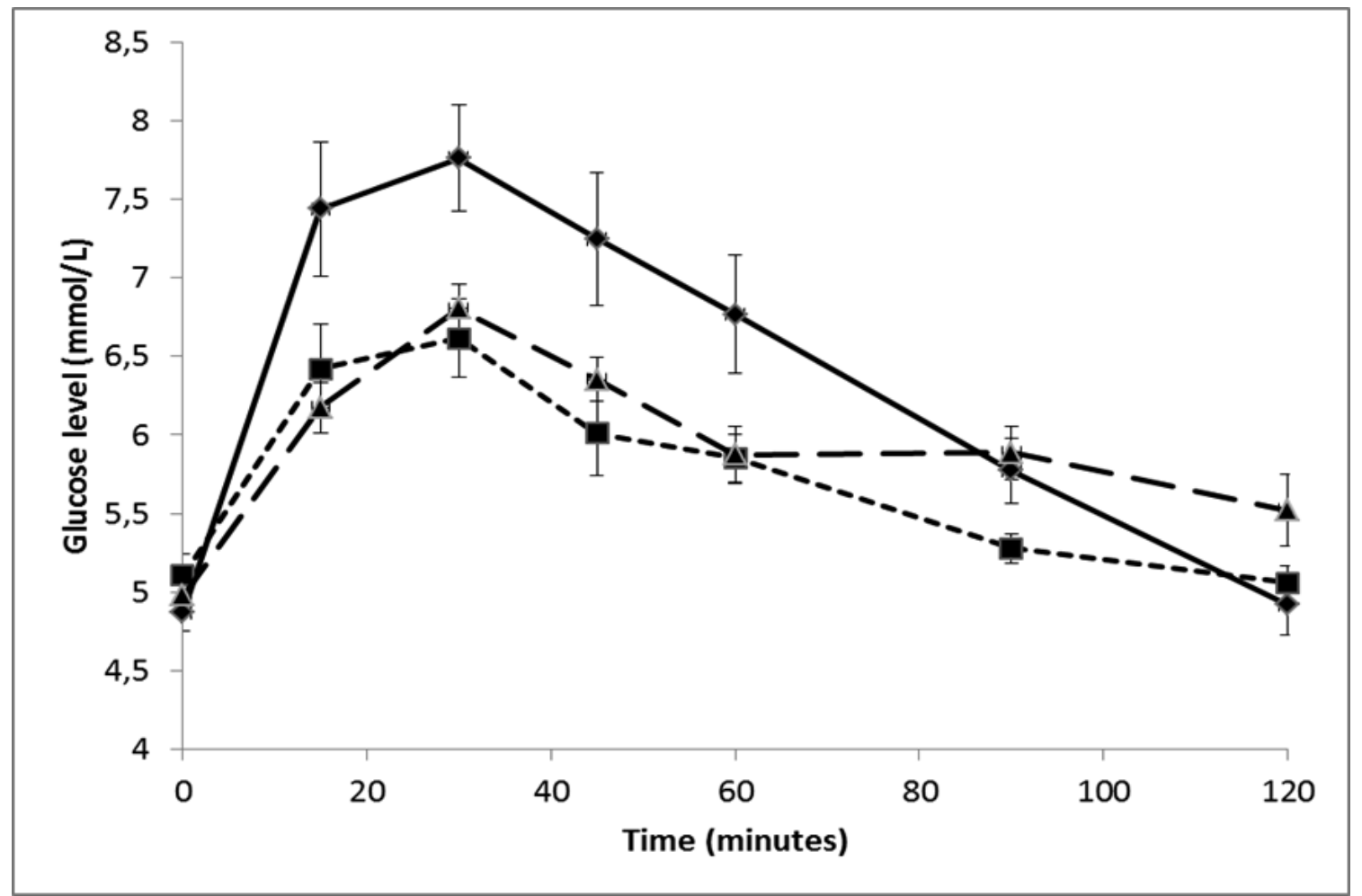

Table 3 The blood glucose incremental areas under the curves (iAUC), Glycemic index, Glycemic Load and Glycemic Profile of VF pasta and DWS pasta. (Data are presented as mean \pm SEM) *p< 0.002 vs DWS pasta; **p< 0.008 vs DWS pasta.

\begin{tabular}{|l|l|l|l|l|}
\hline & $\begin{array}{l}\text { iAUC } \\
\left(\mathbf{m m o l} \mathbf{~ m i n ~ L ~}^{-\mathbf{1}} \text { ) }\right.\end{array}$ & $\begin{array}{l}\text { Glycemic } \\
\text { index }\end{array}$ & $\begin{array}{l}\text { Glycemic } \\
\text { Load }\end{array}$ & $\begin{array}{l}\text { Glycemic } \\
\text { Profile }\end{array}$ \\
\hline VF PASTA & $75 \pm 11 * *$ & $40 \pm 4.5^{*}$ & $20 \pm 2.2^{*}$ & $65 \pm 12$ \\
\hline DWS PASTA & $128 \pm 12$ & $72 \pm 8$ & $37 \pm 4$ & $53 \pm 3$ \\
\hline
\end{tabular}

\section{In vitro inhibitory activity on alfa-glucosidase and alfa-amylase enzyme}

To evaluate potential molecular mechanisms involved in the lower post prandial glycaemia of VF pasta, we compared the in vitro inhibitory activity of VF pasta and DWS pasta extracts on two enzymes involved in carbohydrate digestion (alfa-glucosidase and alfa-amylase). As shown in Table 4, both extracts produced a weak alfa-amylase activity inhibition. A higher inhibitory activity was exerted on alfa-glucosidase activity. As revealed by $\mathrm{IC}_{50}$ values (Table 4), the VF pasta extracts showed a higher inhibitory activity on enzymes with respect to DWS pasta. 
Table 4 Alfa-glucosidase and alfa-amylase inhibition activities of aqueous extracts from the VF and DWS pasta $* \mathrm{p}<0.003$ vs DWF pasta ** $\mathrm{p}<0.002$ vs DWF pasta. Data are presented as mean \pm SEM. Analyses were repeated in triplicate using three samples of each kind of pasta.

\begin{tabular}{|l|l|l|}
\hline \multicolumn{3}{|c|}{ Inhibitory concentration $\left(\mathbf{I C}_{\mathbf{5 0}}\right)(\mathbf{m g} / \mathbf{m L})$} \\
\hline & alfa-glucosidase & alfa-amylase \\
\hline VF PASTA & $9.1 \pm 2.2 *$ & $44.2 \pm 1.7 * *$ \\
\hline DWS PASTA & $18.5 \pm 1.9$ & $69.1 \pm 2.1$ \\
\hline
\end{tabular}

\section{Sensory evaluation}

All 13 subjects completed sensory assessments of VF and DWS pasta. From the sensory evaluation, the value of acceptability of VF pasta was 5.2, slightly lower with respect to 6.1 of DWS pasta. Therefore, the palatability was considered acceptable.

\section{DISCUSSION}

Previous studies have investigated the use of legume flour to develop pasta products with improved quality [26-31]. Among the ingredients used to fortify wheat pasta, flour obtained by different legumes has been used such as soy flour [26], pea flour [27], navy bean flour [28], pinto bean flour [28], Mexican common bean flour [29], lentil bean flour [28], lupin flour [30] and Vicia Faba bean [31]. Until today the effect of Vicia Faba bean flour on polyphenol content, nutritional properties and glycemic index has not been studied in egg pasta. We demonstrated that VF pasta contains higher proteins and fibers compared with DWS pasta. Recent studies have demonstrated that pasta can be considered a source of polyphenols and antioxidants whose levels and composition are strictly related to ingredients and food processing [29,32-37].

Our results have shown that an addition of 35\% Vicia Faba bean flour increases the total polyphenol and total flavonoid content with respect to DWS pasta. Our study has also demonstrated a higher antioxidant potential of the VF pasta, which was evaluated using ORAC assay in respect to DWS pasta. Although phenolic content has shown a good correlation with antioxidant activity in legumes [14], other non-polyphenolic compounds including phytic acid, tocopherols, carotenoids and saponins could collectively contribute to antioxidant activity of VF pasta.

Other authors studied the effect of the addition of different legume flours on glycemic index in cereal-based products and a decrease of GI has been observed [38,39]. Few studies reported the effect of legume flour on glycemic response of pasta. Incorporation of chickpea flour (25\%) into spaghetti resulted in a significantly lower GI (58.9) than traditional spaghetti (72.8) [40]. No changes of GI evaluated in vitro have been observed by Chillo et al. [41] in spaghetti containing $10 \%$ of either mung bean, soya bean, red lentil or chickpea compared with a spaghetti control made only of durum semolina. In contrast, using 30\% whole yellow pea flour to enrich pasta, Marinangeli did not observe significant changes in GI value [42]. Until today, only one study has evaluated glycemic index of pasta with $35 \%$ fava bean [43]. A lower but not significantly lower 
GI has been reported compared with control [43]. In our experimental conditions we demonstrated a lower post prandial increase of glucose levels after intake of VF pasta and a lower glycemic index compared with DWS pasta. Previous studies have demonstrated that different compositional factors can reduce postprandial glucose response such as the total amount and types of fiber [44], protein and fat content [45], starch-protein interactions, and amylose/amylopectin ratio [46]. As aforementioned, in addition to higher fiber and protein content, VF pasta contains higher total polyphenols and total flavonoids. We also suggest that Faba bean polyphenols in VF pasta could be involved in the lower GI. This hypothesis is supported by recent studies in vitro and in vivo which have shown that polyphenols affect the glucose metabolism with different molecular mechanisms such as inhibition of intestinal alfaglucosidase activity [47] and suppression of the elevation of blood glucose concentration after oral administration of glucose in animal models [48,49]. Other authors have demonstrated that polyphenols also exert in vivo an effect on glycemic index with a significant inverse correlation between polyphenol content and GI of pigmented potatoes [50]. Previous studies have shown that Vicia Faba bean polyphenol extracts exert in vitro an inhibitory effect of digestive enzymes and decrease the activity of alfa-glucosidase [16]. Our results demonstrate that the extracts of the pasta were good inhibitors of alfa-glucosidase, but weaker inhibitors of alfa-amylase. These results are in agreement with earlier reports which revealed that plant phytochemicals are mild inhibitors of alfa-amylase and strong inhibitors of alfa-glucosidase activity [51,52]. These properties could confer advantage over synthetic drugs such as Acarbose used by diabetics in the management of post-prandial blood glucose. In fact, Acarbose adverse effects have been related to the excessive pancreatic alfa-amylase inhibition [53].

The use of GI for the classification of carbohydrate-rich foods has been endorsed by the FAO/WHO, who recommended that the GI of foods be considered together with information about food composition to guide food choices [22]. The principle is that the slower the rate of carbohydrate absorption is, the lower the rise of blood glucose level and the lower the GI value will be. A GI value of $\geq 70$ is considered high, a GI value 56-69 inclusive is medium and a GI value $\leq 55$ is low, where glucose $=100$ [22]. Our results demonstrate that GI of VF egg pasta (GI $=40$ ) included in our study is located among low GI foods. Moreover, the GP value of egg pasta containing broad bean flour was higher with respect to control sample. It has been proposed that products characterized by higher GP, indicate a lower glucose peak and a less pronounced hypoglycemia and thus a favorable post-prandial glycaemic response, are more prone to induce benefits on second-meal glucose tolerance as suggested by Rosen et al. [25].

Diabetes appears to be one of the most frequent non-communicable diseases in the world. Hyperglycemia is one of the major problematic symptoms associated with type-2 diabetes mellitus. Moreover, hyperglycemia can lead to cellular damage and contributes to the development of other chronic diseases [8,9]. Several public health organizations have recently integrated consideration of the glycaemic index in their nutritional recommendations for patients with metabolic diseases and for the general population [54]. Moderating postprandial glycemia is a desirable outcome with the European Diabetes Policy Group, advising that postprandial peak glucose fall within $4.0-7.5 \mathrm{mmol} / \mathrm{L}$ for healthy individuals and not exceeds $9 \mathrm{mmol} / \mathrm{L}$ for individuals with diabetes [55]. Therefore, even a modest reduction between $0.5-1.0 \mathrm{mmol} / \mathrm{L}$ in postprandial glucose could be regarded as beneficial to help individuals maintain glucose 
concentrations within upper recommended limits. The GI of foods may also have important implications for the prevention and treatment of other major causes of morbidity and mortality in Western countries, including CVD, obesity and hyperlipidaemia [10,11]. Habitual consumption of high GI foods at high GL is associated with tissue and organ damage such as microangiopathy, diabetic nephropathy or retinopathy whereas low GI foods consumed at moderate GL are associated with reduced rates of coronary arterial diseases and type- 2 diabetes.

\section{CONCLUSIONS}

Our results demonstrate that pasta enriched with Vicia Faba bean has a higher total polyphenol content assessed by Folin-Ciocalteau, more total flavonoids and higher antioxidants as measured by ORAC as well as more fibers. The total polyphenol content and total flavonoid content can be used as important indicators of the antioxidant capacity for any product which is intended to be considered as a natural source of antioxidants in functional foods. Therefore, our results suggest that VF pasta could increase dietary polyphenols intake. The results of GI, GL, and GP confirm that enrichment of egg pasta with 35\% Vicia faba bean exert a beneficial effect and encourages a wider utilization of Faba bean in human diet for its potential health benefits.

Abbreviations: GI: Glycaemic Index; GL: Glycaemic load; GP: Glycaemic Profile; VF: Vicia Faba; DWS: Durum Wheat Semolina; CVD: Cardio-Vascular Diseases; DM: Diabetes Mellitus; BMI: Body Mass Index; iAUC: incremental Area Under Curve glucose; GAE: gallic acid equivalents, ORAC: Oxygen radical absorbance capacity, TPC: total phenolic content, TFC: total flavonoid content.

Author's Contributions: Imma Turco, Tiziana Bacchetti, and Gianna Ferretti contributed to the conceptualisation and design of the study. Imma Turco and Tiziana Bacchetti conducted the study, the analysis of GI and drafted the manuscript. Ganiyu Oboh contributed to in vitro study of pasta extract inhibitory effect on digestive enzymes. Cecilia Bender and Benno Zimmermann ${ }^{5}$ evaluated antioxidant capacities. All authors read and approved the final version of the manuscript.

Acknowledgements and funding: The present study was in part financially supported by a grant from the Agency for Food Service Industry in the Marche (ASSAM). The authors are grateful to Rosatelli Rodolfo (Azienda I Lubachi, PU, Italy) for supplying pasta samples.

Conflict of interest: None of the authors has any conflict of interest to declare.

\section{REFERENCES}

1. Marconi E, Carcea M: Pasta from non traditional materials. Cereal Food World. 2001, 46: 522-530.

2. Asif M, Rooney LW, Ali R, Riaz MN: Application and opportunities of pulses in food system: a review .Crit Rev Food Sci Nutr. 2013, 53:1168-1179. 
3. Zhu BB, Sun Y, Qi L, Zhong R, Miao XP: Dietary legume consumption reduces risk of colorectal cancer: evidence from a meta-analysis of cohort studies. Scientific Reports. 2015,5.

4. Madar Z, Stark AH: New legume sources as therapeutic agents. British Journal of Nutrition. 2002, 88: s287-s292.

5. Bouchenak M, Lamri-Senhadji M: Nutritional quality of legumes, and their role in cardiometabolic risk prevention: a review. J Med Food. 2013, 16(3):185-198.

6. Getek M, Czech N, Muc-Wierzgon M, Grochowska-Niedworok E, Kokot T, Nowakowska-Zajdel E: The Active Role of Leguminous Plant Components in Type 2 Diabetes. Evid Based Complement Alternat Med. 2014;2014:293961.

7. Jenkins DJ, Wolever TM, Taylor RH, Barker H, Fielden H, Baldwin JM, Bowling AC, Newman HC,Jenkins AL, Goff DV: Glycemic index of foods: a physiological basis for carbohydrate exchange. Am J Clin Nutr. 1981, 34(3):362-366.

8. Kawahito S, Kitahata H, Oshita S: Problems associated with glucose toxicity: role of hyperglycemia-induced oxidative stress. World J Gastroenterol. 2009, 15(33): 41374142.

9. Ludwig DDS. The glycemic index - Physiological mechanisms relating to obesity, diabetes, and cardiovascular disease. Journal of the American Medical Association. 2002,287(18):2414-2423.

10. Augustin LS, Franceschi S, Jenkins DJA, Kendall CWC, La Vecchia C: Glycemic index in chronic disease: a review. European Journal of Clinical Nutrition. 2002, 56(11): 1049-1071.

11. Jenkins DJA, Kendall CWC, Augustin LSA, Franceschi S, Hamidi M, Marchie A: Glycemic index: overview of implications in health and disease. American Journal of Clinical Nutrition. 2002, 76(1):s266S-s273

12. Abu-Reidah IM, Contreras MD, Arraez-Roman D, Fernandez-Gutierrez A, SeguraCarretero A: UHPLC-ESI-QTOF-MS-based metabolic profiling of Vicia faba L. (Fabaceae) seeds as a key strategy for characterization in foodomics. Electrophoresis, 2014, 35(11):1571-1581.

13. Bekkara F, Jay M, Viricel MR, Rome S: Distribution of phenolic compounds within seed and seedlings of two Vicia faba cvs differing in their seed tannin content, and study of their seed and root phenolic exudations. Plant and Soil, 1998, 203(1): 27-36.

14. Siah S, Konczak I, Wood JA, Agboola S, Blanchard CL: Effects of Roasting on Phenolic Composition and In vitro Antioxidant Capacity of Australian Grown Faba Beans (Vicia faba L.). Plant Foods for Human Nutrition. 2014,69(1): 85-91.

15. Yuwei L, Weihu X, Zhenping H, Xiaoxiao J, Qian W: The impact of processing on in vitro bioactive compounds bioavailability and antioxidant activities in faba bean (Vicia faba L.) and azuki bean (Vigna angularis L.). International Food Research Journal.2014, 21(3):1031-1037.

16. Siah SD, Konczak I, Agboola S, Wood JA, Blanchard CL: In vitro investigations of the potential health benefits of Australian-grown faba beans (Vicia faba L.): chemopreventative capacity and inhibitory effects on the angiotensin-converting 
enzyme, alpha-glucosidase and lipase. British Journal of Nutrition,2012,108: S123S134.

17. Baldini M, Fabietti F, Giammarioli S, Onori R, Orefici L, Stacchini A: Metodi di analisi utilizzati per il controllo chimico degli alimenti. Rapporti ISTISAN 96/34. 1996

18. Adedayo BC, Ademiluyi AO, Oboh G, Akindahunsi AA: Interaction of aqueous extracts of two varieties of Yam tubers (Dioscorea spp) on some key enzymes linked to type 2 Diabetes in vitro. International Journal of Food Science and Technology. 2012, 47(4): 703-709.

19. Singleton VL, Orthofer R, Lamuela-Raventos RM: Analysis of total phenols and other oxidation substrates and antioxidants by means of Folin-Ciocalteu reagent. Oxidants and Antioxidants. 1999, 299:152-178.

20. Xu BJ, Chang SKC: A comparative study on phenolic profiles and antioxidant activities of legumes as affected by extraction solvents. Journal of Food Science. 2007,72(2):S159-S166.

21. Prior RL, Wu XL, Schaich K: Standardized methods for the determination of antioxidant capacity and phenolics in foods and dietary supplements. Journal of Agricultural and Food Chemistry.2005, 53(10): 4290-4302.

22. FAO. FAO Food Nutr Pap.1998, 66: 1-140.

23. Wolever TM, Csima A, Jenkins DJ, Wong GS, Josse RG : The glycemic index: variation between subjects and predictive difference. J Am Coll Nutr.1989, 8(3):235247

24. Brouns F1, Bjorck I, Frayn KN, Gibbs AL, Lang V, Slama G, Wolever TM: Glycaemic index methodology.Nutr Res Rev. 2005, 18(1):145-171.

25. Rosen LA, Silva LOB, Andersson UK, Holm C, Ostman EM, Bjorck IME: Endosperm and whole grain rye breads are characterized by low post-prandial insulin response and a beneficial blood glucose profile. Nutr J. 2009,25:8:42

26. Matsuo RR, Brandley JW, Iruine GN: Effect of protein content on the cooking quality of spaghetti. . Cereal Chem. 1992, 49:707-711.

27. Nielsen MA, Sumner AK, Whalley LL: Fortification of Pasta with Pea Flour and AirClassified Pea Protein Concentrate. Cereal Chem. 1980,57:203 - 206.

28. Bahnassey Y, Khan K, Harrold R: Fortification of Spaghetti with Edible Legumes. I. Physicochemical, Antinutritional, Amino Acid, and Mineral Composition. Cereal Chem. 1986, 63: 210-215.

29. Gallegos-Infante JA, Rocha-Guzman NE, Gonzalez-Laredo RF, Ochoa-Martinez LA, Corzo N, Bello-Perez LA, Medina-Torres L, Peralta-Alvarez LE: Quality of spaghetti pasta containing Mexican common bean flour (Phaseolus vulgaris L.). Food Chemistry. 2010, 119:1544-1549.

30. Torres A, Frias J, Granito M, Guerra M, Vidal-Valverde, C: Chemical, biological and sensory evaluation of pasta products supplemented with alpha-galactoside-free lupin flours. Journal of the Science of Food and Agriculture. 2007,87(1): 74-81.

31. Tazrart K, Zaidi F, Lamacchia C, Haros M: Effect of durum wheat semolina substitution with broad bean flour (Vicia faba) on the Maccheronccini pasta quality. Eur Food Res Technol.2016, 242:477-485. 
32. Durazzo A, Turfani V, Azzini E, Maiani G, Carcea M: Antioxidant Properties of Experimental Wholegrain Pastas Made With Different Cereals. Journal of Food Research.2014,3(4): 33-40.

33. Fares C, Platani C, Baiano A, Menga V: Effect of processing and cooking on phenolic acid profile and antioxidant capacity of durum wheat pasta enriched with debranning fractions of wheat. Food Chemistry. 2010, 119(3): 1023-1029.

34. Seczyk L, Swieca M, Gawlik-Dziki U: Effect of carob (Ceratonia siliqua L.) flour on the antioxidant potential, nutritional quality, and sensory characteristics of fortified durum wheat pasta. Food Chemistry.2016, 194:637-642.

35. Seczyk L, Swieca M, Gawlik-Dziki U, Luty M, Czyz J: Effect of fortification with parsley (Petroselinum crispum Mill.) leaves on the nutraceutical and nutritional quality of wheat pasta. Food Chemistry. 2016, 190: 419-428

36. Khan I, Yousif AM, Johnson SK, Gamlath S: Acute effect of sorghum flour-containing pasta on plasma total polyphenols, antioxidant capacity and oxidative stress markers in healthy subjects: A randomised controlled trial. Clinical Nutrition. 2015, 34(3): 415421.

37. Zeppa G, Belviso S, Bertolino M, Cavallero MC, Dal Bello B, Ghirardello D : The effect of hazelnut roasted skin from different cultivars on the quality attributes, polyphenol content and texture of fresh egg pasta. Journal of the Science of Food and Agriculture. 2015,95(8):1678-1688.

38. Zafar TA, Al-Hassawi F, Al-Khulaifi F, Al-Rayyes G, Waslien C, Huffman FG: Organoleptic and glycemic properties of chickpea-wheat composite breads. J Food Sci Technol. 2015, 52(4):2256-2263.

39. Johnson SK, Thomas SJ, Hall RS: Palatability and glucose, insulin and satiety responses of chickpea flour and extruded chickpea flour bread eaten as part of a breakfast. Eur J Clin Nutr. 2005, 59(2):169-176.

40. Goni I, Valentin-Gamazo C. Chickpea flour ingredient slows glycemic response to pasta in healthy volunteers. Food Chemistry.2003,81(4): 511-515.

41. Chillo S, Monro JA, Mishra S, Henry CJ. Effect of incorporating legume flour into semolina spaghetti on its cooking quality and glycaemic impact measured in vitro. International Journal of Food Sciences and Nutrition, 2010, 61(2):149-160.

42. Marinangeli CPF, Kassis AN, Jones PJH: Glycemic Responses and Sensory Characteristics of Whole Yellow Pea Flour Added to Novel Functional Foods. Journal of Food Science.2009,74(9):S385-S389.

43. Greffeuille V, Marsset-Baglieri A, Molinari N, Cassan D, Sutra T, Avignon A: Enrichment of pasta with faba bean does not impact glycemic or insulin response but can enhance satiety feeling and digestive comfort when dried at very high temperature. Food \& Function.2015, 6(9):2996-3005.

44. Scazzina F, Siebenhandl-Ehn S, Pellegrini N: The effect of dietary fibre on reducing the glycaemic index of bread. British Journal of Nutrition. 2013,109(7):1163-1174.

45. Collier G, O'Dea K:The effect of coingestion of fat on the glucose, insulin, and gastric inhibitory polypeptide responses to carbohydrate and protein. Am $\mathrm{J}$ Clin Nutr.1983,37(6): 941-944. 
46. Thorne MJ, Thompson LU, Jenkins DJ: Factors affecting starch digestibility and the glycemic response with special reference to legumes. Am J Clin Nutr.1983, 38(3): 481-488.

47. Pereira DF, Cazarolli L H, Lavado C, Mengatto V, Figueiredo MS, Guedes A: Effects of flavonoids on alpha-glucosidase activity: potential targets for glucose homeostasis. Nutrition. 2011,27(11-12) : 1161-1167.

48. Dragan S, Andrica F, Serban MC, Timar R: Polyphenols-Rich Natural Products for Treatment of Diabetes. Current Medicinal Chemistry. 2015, 22(1) : 14-22.

49. Hanhineva K, Torronen R, Bondia-Pons I, Pekkinen J, Kolehmainen M, Mykkanan H: Impact of Dietary Polyphenols on Carbohydrate Metabolism. International Journal of Molecular Sciences. 2010,11(4): 1365-1402.

50. Ramdath DD, Padhi E, Hawke A, Sivaramalingam T, Tsao R: The glycemic index of pigmented potatoes is related to their polyphenol content. Food \& Function. 2014,5(5): 909-915.

51. Bhat M, Zinjarde SS, Bhargava SY, Kumar AR, Joshi BN: Antidiabetic Indian Plants: A Good Source of Potent Amylase Inhibitors. Evidence-Based Complementary and Alternative Medicine. 2011:1-6.

52. Kwon YI, Apostolidis E, Kim YC, Shetty K: (Health benefits of traditional corn, beans, and pumpkin: In vitro studies for hyperglycemia and hypertension management. Journal of Medicinal Food. 2007,10(2) : 266-275.

53. Oboh, G., Akinyemi, A. J., \& Ademiluyi, A. O. Inhibition of $\alpha$-amylase and $\alpha$ glucosidase activities by ethanolic extract of Telfairia occidentalis (fluted pumpkin) leaf Asian Pac J Trop Biomed. 2012, 2(9) : 733-738.

54. Rizkalla SW, Bellisle F, Slama G: Health benefits of low glycaemic index foods, such as pulses, in diabetic patients and healthy individuals. British Journal of Nutrition. 2002,88: S255-S262.

55. Aguilar M, Alberti KGM, Amiel SA, Azzopardi J, Berne C, Bilous RW: A desktop guide to Type 1 (insulin-dependent) diabetes mellitus. Diabetic Medicine. 1999,16(3) : 253-266. 